\title{
COMPARISON OF PERIOPERATIVE MAGNESIUM SULPHATE INFUSION WITH PLACEBO FOR POSTOPERATIVE ANALGESIA.
}

\footnotetext{
1. FCPS Anesthesiology Senior Registrar Department of Anesthesia Nishtar Medical University, Multan.

2. FCPS Anesthesiology Senior Registrar Department of Anesthesia Ch. Pervaiz Elahi Institute of Cardiology, Multan.

3. FCPS Anesthesiology Consultant Department of Anesthetist King Khalid Hospital, Saudi Arabia.

4. FCPS (Cardiology)

Assistant Professor Department of Cardiology University Medical \& Dental College, Faisalabad
}

Correspondence Address: Dr. Afifa Zahoor

Zahoor Villa Kotla Waris Shah

Chungi Number 1, Multan.

afifazahoor@gmail.com

Article received on: 05/03/2019

Accepted for publication: 05/07/2019

\begin{abstract}
Ranna Mussrat ${ }^{1}$, Afifa Zahoor ${ }^{2}$, Muhammad Ahmad Khan ${ }^{3}$, Shakeel Ahmad
ABSTRACT: Adequate control of post-operative pain is very essential to reduce discomfort and early recovery after surgery. Role of adjuvant drugs along with conventional analgesic drugs have gained popularity in recent years, out of which $\mathrm{MgSO}_{4}$ is one of them. Objectives: To compare mean duration of postoperative analgesia between perioperative infusion of magnesium sulfate versus placebo in patients undergoing upper abdominal surgery. Study Design: Randomized Controlled Trial. Setting: Nishtar Medical University/Hospital Multan. Period: March-2018 to Dec-2018. Material and Methods: A total number of 100 patients admitted for upper abdominal surgery in the Department of Surgery, Nishtar Hospital Multan were included in this analysis. Group A received $50 \mathrm{mg} / \mathrm{kg} \mathrm{i} / \mathrm{v}$ of $\mathrm{MgSO}_{4}$ in $0.9 \% \mathrm{~N} / \mathrm{S}$ at induction and $15 \mathrm{mg} / \mathrm{kg} \mathrm{MgSO}$, per hour, 6 hours postoperatively. While group B received $100 \mathrm{ml}$ of $0.9 \% \mathrm{~N} / \mathrm{S}$ at induction and 500 $\mathrm{ml}$ of $0.9 \% \mathrm{~N} / \mathrm{S} 6$ hours postoperatively. Post-op pain score was noted at 01 and 06 hours after surgery. Time for requirement of first rescue analgesia was also noted. Results: Mean post-op pain (VAS score) after 01 hour of surgery was $2.7+0.43$ in $\mathrm{MgSO}_{4}$ group versus $4.1+0.82$ in control group ( $p$-value <0.001). VAS score after 06 hours was $1.9+0.31$ in $\mathrm{MgSO}_{4}$ group versus $2.3+0.63$ in control ( $\mathrm{p}$-value $<0.001$ ). Time of first rescue analgesia was prolonged in $\mathrm{MgSO}_{4}$ group; $105.9+12.7$ minutes versus $67.8+15.3$ minutes in control group with $p$-value $<0.001$. Conclusion: Magnesium sulfate increases the duration of postoperative analgesia and can be used as an adjunct since this molecule is inexpensive, relatively harmless, and the biological basis for its potential anti-nociceptive effect is promising.
\end{abstract}

Key words: $\quad$ Magnesium Sulphate, Post-op Pain, Upper Abdominal Surgery.

Article Citation: Mussrat R, Zahoor A, Khan MA, Ahmad S. Comparison of perioperative magnesium sulphate infusion with placebo for postoperative analgesia. Professional Med J 2019; 26(11):1937-1941.

DOI: 10.29309/TPMJ/2019.26.11.3381

\section{INTRODUCTION}

Adequate control of post-operative pain is very essential to reduce discomfort and early recovery after surgery. Inadequate pain management is a major risk of increased morbidity and quality of life after surgery. ${ }^{1}$ Pain alters the body physiology in many ways. Pain increases heart rate, blood pressure, oxygen consumption and minute ventilation. Pain causes anxiety, depresses immune system and increase release of catabolic hormones. Postoperative pain falls in category of acute pain which is sharp, lacerating in character. ${ }^{2,3}$

Commonly employed methods for treating postoperative pain are conventional use of opioids, NSAIDS \& paracetamol through various routes, central neuraxial blocks, peripheral nerve blocks, local anesthetic infiltration of wound.4-7 Moreover, nonconventional therapy for postoperative pain includes use of adjuncts to conventional therapy like $\mathrm{MgSO}_{4}$, Clonidine, Reserpine, Neostigmine, use of antidepressants and anticonvulsants, transcutaneous electrical nerve stimulation (TENS), acupuncture, radiofrequency ablation (RFA), cryoanalgesia and rhizotomy. ${ }^{8-10}$ In addition to relieve pain, $\mathrm{MgSO}_{4}$ is also used in treatment of torsade de pointes, quinidine induced arrhythmias, as a bronchodilator in severe asthmatic attacks, as anticonvulsant in eclampsia, to delay preterm birth, to prevent cerebral palsy in preterm babies, calcium channel blocker over dosage and migraine and is recommended in various text books of different specialties. ${ }^{11}$ 
Magnesium exerts its analgesic activity by acting on NMDA receptors. ${ }^{12}$ It has been used from several decades for management of pain. ${ }^{13}$ Among the various routes of administration, the systemic route is the preferred one. Some studies have found that the use of $\mathrm{MgSO}_{4}$ is beneficial, ${ }^{14,15}$ while some have reported opposite results. ${ }^{16}$ A meta-analysis by Guo et al. have concluded that $\mathrm{MgSO}_{4}$ is beneficial for prevention of postoperative pain, but data is still pre-mature in published trials to draw conclusion that $\mathrm{MgSO}_{4}$ should be administrated routinely for postoperative pain management. ${ }^{17}$ So the present study is designed to compare mean duration of postoperative analgesia between perioperative infusion of magnesium sulfate versus placebo in patients undergoing upper abdominal surgery.

\section{METHODOLOGY}

A total number of 100 patients of ASA grade I and II, who had to undergo different types of elective surgery for upper abdomen like cholecystectomy, gastrostomy, liver abscess, right hemicolectomy from March-2018 to Dec-2018 was included in this study.

Patient with prior surgery, on calcium channel blocker, renal dysfunction, major systemic illness, history of neuropathy, myopathy were excluded. The study was conducted in the department of general surgery Nishtar Hospital Multan.

The sample size for this study is based on the results of study of Kiran et al., by taking VAS score $1.32 \pm 0.84$ in $\mathrm{MgSO}_{4}$ group and $1.32 \pm 0.84$ in placebo group after 4 hours of surgery. ${ }^{14}$ At power of the test $80 \%$ and level of significance $5.0 \%$. the sample size was 23 patients in each group. We took 50 patients in each group to make the study results more accurate.

All the patients were preoperatively examined in detail to get detailed clinical history and basic demographic information. On the morning of surgery, we divided patients randomly into two groups by Draw Method. Group A received 50 $\mathrm{mg} / \mathrm{kg} \mathrm{l} / \mathrm{v}$ of $\mathrm{MgSO}_{4}$ in $0.9 \% \mathrm{~N} / \mathrm{S}$ at induction and $15 \mathrm{mg} / \mathrm{kg} \mathrm{MgSO} /$ /hour, 6 hours postoperatively. While group $B$ received $100 \mathrm{ml}$ of $0.9 \% \mathrm{~N} / \mathrm{S}$ at induction and $500 \mathrm{ml}$ of $0.9 \% \mathrm{~N} / \mathrm{S} 6$ hours postoperatively.

All the patients received inj. Midazolam $(0.1 \mathrm{mg} / \mathrm{kg})$ and Nalbuphine $(0.1 \mathrm{mg} / \mathrm{kg})$ for premedication. For induction we used Inj.

Propofol (2 mg/kg), Atracurium (0.5 mg/kg), $\mathrm{N}_{2} \mathrm{O} \& \mathrm{O}_{2}(60: 40)$ and Sevoflurane titrated to keep B.P $+20 \%$ of baseline value for maintenance, inj. Atropine $(0.02 \mathrm{mg} / \mathrm{kg})$ and inj. Neostigmine (0.05 mg/kg) postoperatively for reversal of neuromuscular blockade.

Total duration of analgesia, and time for requirement of first rescue analgesia was noted. Inj. Tramadol 2-3 $\mathrm{mg} / \mathrm{kg}$ iv was as rescue analgesic.

Data analysis was performed using SPSS v23. Independent sample t-test was used for comparison of age, VAS pain score and time for requirement of first analgesia. Gender and type of surgery was compared using Independent sample t-test. P-value $<0.05$ was considered significant.

\section{RESULTS}

In Table-I, data of patients' demographics and types of procedures is presented. There was no difference (statistically) in age, gender and $\mathrm{BMl}$ between the $\mathrm{MgSO}_{4}$ and control group. Indications of surgical exploration were liver pathology in $11 \%$ patients, gallbladder pathology in $48 \%$ patients stomach cancer in $14 \%$ and cholo-rectal pathology in $27 \%$ patients.

Mean post-op pain (VAS score) after 01 hour of surgery was $2.7+0.43$ in $\mathrm{MgSO}_{4}$ group versus $4.1+0.82$ in control group ( $p$-value $<0.001$ ). VAS score after 06 hours was $1.9+0.31$ in $\mathrm{MgSO}_{4}$ group versus $2.3+0.63$ in control ( $p$-value $<0.001$ ). Time of first rescue analgesia was prolonged in $\mathrm{MgSO}_{4}$ group; 105.9+12.7 minutes versus $67.8+15.3$ minutes in control group with p-value $<0.001$ (Table-II). 


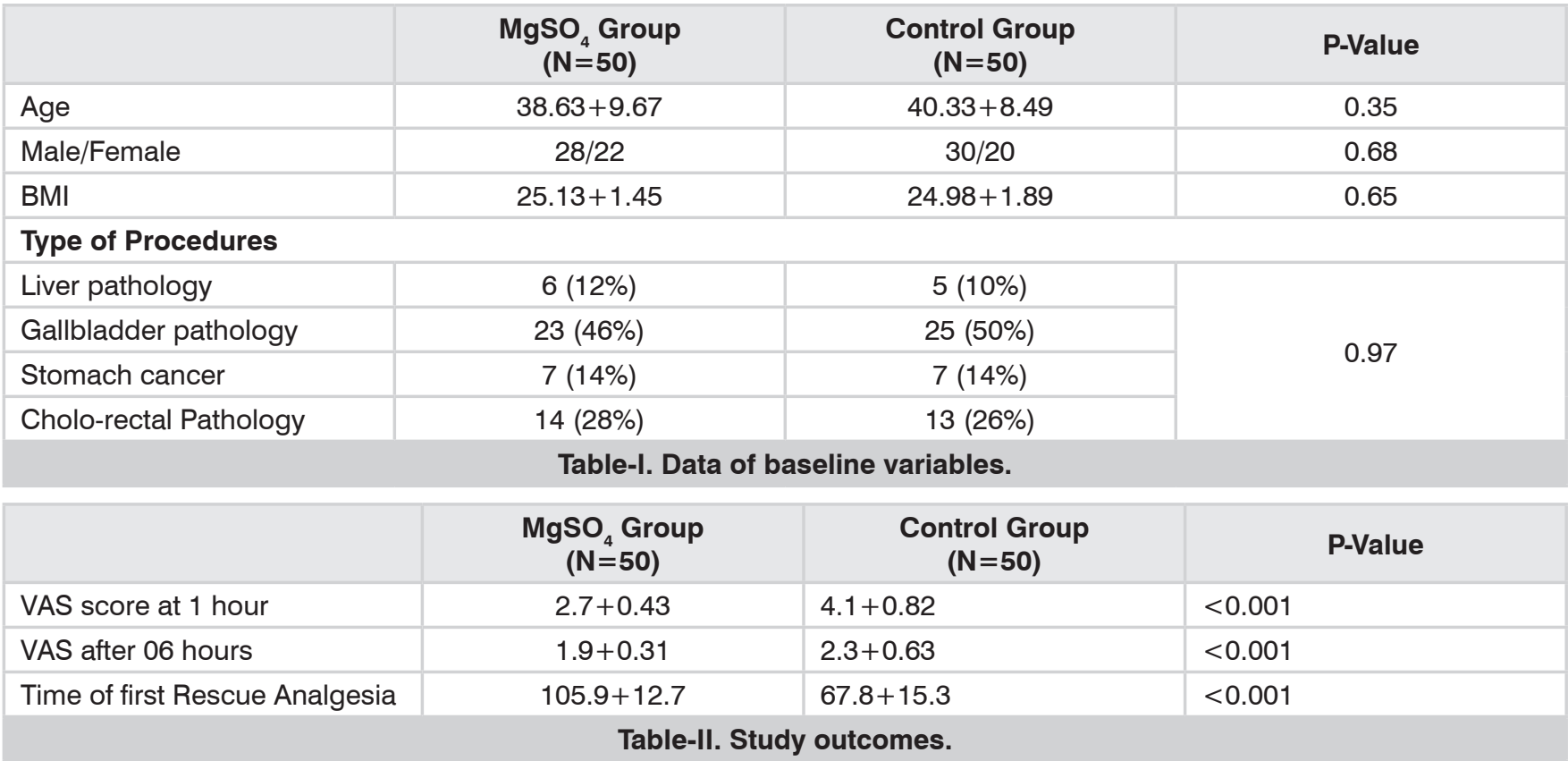

\section{DISCUSSION}

Post-op pain is a major risk of psychological and physical trauma in the operated patients. ${ }^{18}$ Therefore, anesthetists have tried various drugs and techniques to reduce its incidence. ${ }^{19} \mathrm{MgSO}_{4}$ is one of these drug, it is a NMDA receptor antagonist and have analgesic properties. Its blocks NMDA receptors activity by antagonizing calcium channels of different voltage. ${ }^{20,21}$

In present study we evaluated the role of peri-op $\mathrm{MgSO}_{4}$ infusion in patients of upper abdominal surgery. We found lower post-op pain and longer duration of analgesia by using $\mathrm{MgSO}_{4}$ as compared to the control group.

In a study by Usmani et al. also found beneficial effects of magnesium infusion. They found mean VAS score 4.5 in $\mathrm{MgSO}_{4}$ versus 5.6 in control group after 01 hour and 4.3 versus 4.0 after 6 hours respectively. ${ }^{22}$

Shah et al. conducted a study on intra-op $\mathrm{MgSO}_{4}$ administration in patients under spinal anesthesia. they found mean analgesia time of $154.89 \pm 18.73$ minutes in MgSO4 versus 120.52 \pm 11.12 minutes in control group. The authors concluded that the $\mathrm{MgSO}_{4}$ infusion reduces and delays the need of rescue analgesics. ${ }^{21}$
Ghaffaripour et al. did not found any significant effect of $\mathrm{MgSO}_{4}$ infusion, they reported mean VAS score of 3.89+1.19 in $\mathrm{MgSO}_{4}$ versus 3.85+0.87 in control group with insignificant difference. ${ }^{23}$

Kogler evaluated the role of $\mathrm{MgSO}_{4}$ during thoracotomy procedures. They found significant reduction in the requirements of sedative drugs, but the author did not found any significant difference in post-op pain score between the groups. ${ }^{24}$

Taheri et al. uses low dose of $\mathrm{MgSO}_{4}$ in patients undergoing hysterectomy under general anesthesia. they found significant effects of lower dose of $\mathrm{MgSO}_{4}$ on post-op pain. More-over the authors gave only single dose of magnesium and found it effective in reducing post-op pain. ${ }^{25}$

\section{CONCLUSION}

Magnesium sulfate increases the duration of postoperative analgesia and can be used as an adjunct since this molecule is inexpensive, relatively harmless, and the biological basis for its potential antinociceptive effect is promising.

\section{Copyright $\odot 05$ July, 2019.}

\section{REFERENCES}

1. Voscopoulos $C$, LemaM. When does acute pain become chronic? Br J Anaesth. 2010; 105(suppl_1):i69-i85. 
2. Saccò $M$, Meschi M, Regolisti G, Detrenis S, Bianchi $L$, Bertorelli $M$, et al. The relationship between blood pressure and pain. J Clin Hypertens. 2013; 15(8):6005.

3. Carr EC. Exploring the effect of postoperative pain on patient outcomes following surgery. Acute Pain. 2000; 3(4):183-93.

4. Merry A, Gibbs R, Edwards J, Ting G, Frampton C, Davies $E$, et al. Combined acetaminophen and ibuprofen for pain relief after oral surgery in adults: $A$ randomized controlled trial. Br J Anaesth. 2010; 104(1):80-8.

5. Gupta R, Kaur S, Singh S, Aujla K. A comparison of epidural butorphanol and tramadol for postoperative analgesia using CSEA technique. J Anaesthesiol, Clin Pharmacol. 2011; 27(1):35-8.

6. Asad N, Afzal F, Khawar A, Hanif A, Saleem H, Hussain $S$. Genitofemoral nerve block and intraoperative analgesia in children during inguinal hernia repair. Biomedica. 2009; 25:146-9.

7. Al-hakim NH, Alidreesi Z. The effect of local anaesthetic wound infiltration on postoperative pain after caesarean section. J Surg Pak. 2010; 15(3):13134.

8. Ghatak T, Chandra G, Malik A, Singh D, Bhatia VK. Evaluation of the effect of magnesium sulphate vs. clonidine as adjunct to epidural bupivacaine. Indian J Anaesth. 2010; 54(4):308-13.

9. Yameen F, Shahbaz NN, Hasan Y, Fauz R, Abdullah $M$. Efficacy of transcutaneous electrical nerve stimulation and its different modes in patients with trigeminal neuralgia. J Pak Med Assoc. 2011; $61(5): 437-9$.

10. Ahsin S, Aslam M, Saleem S, Bhatti AM. Role of electroacupuncture in treatment of osteoarthritis knee: A single blind sham controlled study. Rawal Med J. 2010; 35(1):41-4.

11. Hunter LA, Gibbins KJ. Magnesium sulfate: Past, present, and future. Journal of Midwifery \& Women's Health. 2011; 56(6):566-74.

12. Zhu S, Stein RA, Yoshioka C, Lee C-H, Goehring A, Mchaourab HS, et al. Mechanism of NMDA receptor inhibition and activation. Cell. 2016; 165(3):704-14.

13. de Oliveira GS, Castro-Alves LJ, Khan JH, McCarthy RJ. Perioperative systemic magnesium to minimize postoperative pain: A meta-analysis of randomized controlled trials. Surv Anesthesiol. 2016; 60(4):166-7.
14. Kiran S, Gupta R, Verma D. Evaluation of a single-dose of intravenous magnesium sulphate for prevention of postoperative pain after inguinal surgery. Indian $\mathrm{J}$ Anaesth. 2011; 55(1):31-5.

15. Do S-H. Magnesium: A versatile drug for anesthesiologists. Korean J Anesthesiol. 2013; 65(1):4-8.

16. Tramèr MR, Glynn CJ. An evaluation of a single dose of magnesium to supplement analgesia after ambulatory surgery: Randomized controlled trial. Anesth Analg. 2007; 104(6):1374-9.

17. Guo BL, Lin Y, Hu W, Zhen CX, Bao-Cheng Z, Wu HH, et al. Effects of systemic magnesium on post-operative analgesia: Is the current evidence strong enough. Pain Physician. 2015; 18:405-17.

18. Kehlet $H$. Surgical stress: The role of pain and analgesia. Br J Anaesth. 1989; 63(2):189-95.

19. Gordon DB, de Leon-Casasola OA, Wu CL, Sluka KA, Brennan TJ, Chou R. Research gaps in practice guidelines for acute postoperative pain management in adults: Findings from a review of the evidence for an American Pain Society Clinical Practice Guideline. J Pain. 2016; 17(2):158-66.

20. Coderre TJ, Katz J, Vaccarino AL, Melzack R. Contribution of central neuroplasticity to pathological pain: Review of clinical and experimental evidence. Pain. 1993; 52(3):259-85.

21. Shah PN, Dhengle Y. Magnesium sulfate for postoperative analgesia after surgery under spinal anesthesia. Acta Anaesthesiol Taiwanica. 2016; 54(2):62-4.

22. Usmani H, Quadir A, Alam M, Rohtagi A, Ahmed G. Evaluation of perioperative magnesium sulphate infusion on postoperative pain and analgesic requirements in patients undergoing upper abdominal surgery?. J Anaesthesiol Clin Pharmacol. 2007; 23(3):255-8.

23. Ghaffaripour $\mathrm{S}$, Mahmoudi $\mathrm{H}$, Eghbal $\mathrm{H}$, Rahimi A. The effect of intravenous magnesium sulfate on postoperative analgesia during laminectomy. Cureus. 2016; 8(6).

24. Kogler J. The analgesic effect of magnesium sulfate in patients undergoing thoracotomy. Acta Clin Croat. 2009;48(1):19-26.

25. Taheri A, Haryalchi K, Mansour Ghanaie M, Habibi Arejan N. Effect of low-dose (single-dose) magnesium sulfate on postoperative analgesia in hysterectomy patients receiving balanced general anesthesia. Anesthesiol Res Pract. 2015; 2015. 


\section{AUTHORSHIP AND CONTRIBUTION DECLARATION}

\begin{tabular}{|c|c|c|c|}
\hline Sr. \# & Author(s) Full Name & Contribution to the paper & Author(s) Signature \\
\hline 1 & Ranna Mussrat & $\begin{array}{l}\text { Conceived, designed, data } \\
\text { analysis and editing of manuscript. }\end{array}$ & 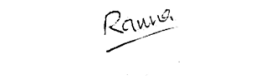 \\
\hline 2 & Afifa Zahoor & $\begin{array}{l}\text { Did data collection and manuscript } \\
\text { writing. }\end{array}$ & \\
\hline 3 & M. Ahmad Khan & $\begin{array}{l}\text { Helped in writing the manuscript } \\
\text { and did review and approved the }\end{array}$ & \\
\hline 4 & Shakeel Ahmad & $\begin{array}{l}\text { final version for publication. } \\
\text { 4th Author }\end{array}$ & \\
\hline
\end{tabular}

